The local committees would recommend appropriate safety precautions for every research proposal and then pass the matter to the national body, which has the final word.

The Academy decided that Israeli researchers would in general follow the NIH guidelines but would take into consideration recommendations from other bodies.

\section{International catalogue}

For Europe's researchers, worry as well as confusion is the product of the growing involvement of an increasing number of international bodies. But the important issue-whether or not there should be harmonisation of guidelines-already seems settled. There were benefits in allowing each country to follow its own path and arrive at its own conclusions, but different precautions in different countries threatened to encourage a concentration of researchers, so harmonisation looked preferable.

Moreover, with the subject a matter for public debate, there was the possibility that if one country applied more stringent controls than another, the difference itself could become an issue. Harmonisation could pose problems, though, if US researchers are faced with legally enforced regulations and there is public pressure for similar regulations in Europe. Creating a disinterested peer group competent to judge colleagues' work could be difficult enough without the added (if necessary) complication of drafting and enforcing legislation.

The case for harmonisation does not, however, solve the problem of which body has the authority to encourage the move towards it. A look at the organisations involved reveals the difficulty.

The World Health Organisation (WHO). The WHO has two bodies actively involved, the WHO Special Programme on Safety Measures in Microbiology and the WHO Environmental Programme. Being global and not confined to Europe, and concerned with the public heaith and safety aspects of the research, the WHO interest is peripheral as yet, although it has begun consultations, with, for example, Professor S. W. Glover, chairman of the International Microbial Genetics Commission, which has a genetic engineering sub-group.

The International Council of Scientific
Unions (ICSU). ICSU has recently created a sub-committee known as COGENE, headed by the US microbiologist Bill Whelan. Its first official meeting is in Paris at the end of May. Because it too is part of a global agency, and because it represents international commissions in various disciplines more than national councils, ICSU can acquire an important role outside North America and Western Europe.

It can, for example, involve the East European countries and also the USSR, which is apparently keen to participate in the research under agreed guidelines-the USSR has a committee under Professor Bayev which hopes to produce its own guidelines by the middle of the year. ICSU can also involve important Third World countries, such as India and Nigeria, which cannot be prevented from pursuing the research but which might participate in any programme organised by ICSU on their behalf to help ensure that they take the necessary precautions.

The European Molecular Biology Organisation (EMBO). EMBO is based at Heidelberg, where a P4 facility for international use is under construction.

\title{
Britain's GMAG gets going
}

BRITAIN's Genetic Manipulation Advisory Group (GMAG) has already given outline approval to more than half a dozen experiments, including one that requires the highest level of containment. For the present, however, the only place where such an experiment can be carried out is Porton, a Ministry of Defence establishment whose future is under scrutiny.

GMAG meets monthly to consider proposals for genetic manipulation experiments which, while awaiting a legal definition, are taken to refer to those in which restriction enzyme fragments of nucleic acids are recombined with the genomes of other organisms in which they are capable of propagation. GMAG's chairman is Sir Gordon Wolstenholme; it has 19 members, of whom only three have a direct interest in recombinant DNA research. Most of the others are biological scientists, but there are four union representatives and two nonscientific academics.

It is GMAG's task to consider any proposals and to state its objections, if any. Proposals (25 copies) are submitted on a formidable form on which ful details of the protocol, personnel and facilities have to be provided along with information rcgarding local safety committees, biological safety officers, medical officers and health monitoring schemes. Proposed experiments fall into four categories. depending on the associated hazards. It is up to the proposers to categorise their own experiments but up to GMAG to ascertain whether the relevant requirements are satisfied.

In the case of the two categories (III and IV) that represent the greatest hazards, GMAG has to carry out a site inspection of the facilities. This they have already done for the category III facility at the MRC Mammalian Genome Unit in Edinburgh. Professor Peter Walker of that unit expresses himself well satisfied with the visit and its outcome which, pending attention to a few minor problems, should give him the first approved category III facility in Britain. Site visits have also been requested for a proposed category III laboratory at Imperial College and for the Microbiological Research Establishment at Porton. It is on Porton that British shortterm hopes for a category IV facility hang-though for now on some rather delicate strings. Porton is the property of the Ministry of Defence and has been the laboratory in which much of Britain's microbiological warfare research has been carried out. As such it has long been unloved by many academics. Now it is also unloved by the Ministry, which recently announced that it no longer has a use for the microbiological laboratories. Since December their future has been uncertain and is now the subject of a confidential report prepared by the Central Policy Review Staff for the Cabinet (see Britain, page 9). A decision is thought to be imminent.

There are bound to be problems if the decision leaves the laboratories under the control of the Ministry of Defence. If that happened, it is known that a faction of GMAG. led by some of the trade union representatives, would be strongly opposed to the usc of Porton's facilities for civil genetic manipulation. That could prevent the go-ahead of any category IV experiments, including the one that has already been given outline approval. until an alternative category IV laboratory could be found. At the moment none are planned but it would not be too far-fetched to suppose that the proposed category III facility currently being completed at the Beatson Institute. Glasgow, could be upgraded if required.

It is Scottish laboratories that have so far taken the lead in applying to GMAG, with their English counterparts being distinctly slow off the mark. Of the expected initial batch of 40-50 applications less than 15 had reached GMAG by its third meeting last month and at least eight of those were from north of the border, mainly from Professor Walker's laboratory.

GMAG has in fact expressed surprise at the paucity of applications and has reminded those concerned that they would be foolish not to present their proposals to the group. At present application to GMAG is voluntary although the UK Health and Safety Commission (HSC) is redrafting its controversial regulations that would make notification compulsory. The original proposals were strongly criticised for being far too wide-ranging, especially as existing health and safety regulations already cover the laboratory hazards of genetic manipulation in the general sense.

The Research Councils have themselves warned of their intention of withdrawing funding of any rogue manipulators. Only industry would therefore be immune from financial sanctions, but the two most interested pharmaceutical companies have already made their intentions clear by submitting proposals to GMAG.

Peter Newmark 